\section{(1)}

CrossMark

\title{
Call for urgent actions to ensure access to early diagnosis and care of tuberculosis among refugees
}

\author{
Statement of the European Respiratory Society and the European Region of the \\ International Union Against Tuberculosis and Lung Disease
}

\author{
Masoud Dara ${ }^{1}$, Ivan Solovic ${ }^{2}$, Giovanni Sotgiu $^{3}$, Lia D’Ambrosio ${ }^{4,5}$, \\ Rosella Centis ${ }^{4}$, Delia Goletti ${ }^{6}$, Raquel Duarte ${ }^{7}$, Stefano Aliberti ${ }^{8}$, \\ Fernando Maria de Benedictis ${ }^{9}$, Graham Bothamley ${ }^{10}$, Tom Schaberg ${ }^{11}$ \\ Ibrahim Abubakar ${ }^{12}$, Brian Ward ${ }^{13}$, Vitor Teixeira ${ }^{13}$, Christina Gratziou ${ }^{14}$ and \\ Giovanni Battista Migliori ${ }^{4}$
}

\begin{abstract}
Affiliations: ${ }^{1}$ World Health Organization Office at the European Union, Brussels, Belgium. ${ }^{2}$ National Institute for TB, Lung Diseases and Thoracic Surgery, Vysne Hagy, Catholic University Ruzomberok, Ruzomberok, Slovakia. ${ }^{3}$ Clinical Epidemiology and Medical Statistics Unit, Dept of Biomedical Sciences, University of Sassari, Research, Medical Education and Professional Development Unit, AOU Sassari, Sassari, Italy. ${ }^{4}$ WHO Collaborating Centre for TB and Lung Diseases, Fondazione S. Maugeri IRCCS, Tradate, Italy. ${ }^{5}$ Public Health Consulting Group, Lugano, Switzerland. ${ }^{6}$ National Institute for Infectious Diseases, Rome, Italy. ${ }^{7} \mathrm{EPI}$ Unit, Institute of Public Health, University of Porto, Porto, Portugal. ${ }^{8}$ School of Medicine and Surgery, University of Milan-Bicocca, UO Clinica Pneumologica, AO San Gerardo, Monza, Italy. ${ }^{9}$ Paediatric Italian Society, Section Marche, Ancona, Italy. ${ }^{10}$ Dept of Respiratory Medicine, Homerton University Hospital NHS Foundation Trust, London, UK. ${ }^{11}$ Dept of Pneumology, Deaconess Hospital Rotenburg, Rotenburg (Wümme), Germany. ${ }^{12}$ Centre for Infectious Disease Epidemiology, UCL and Tuberculosis Section, Public Health England, London, UK. ${ }^{13}$ European Respiratory Society, EU Affairs Dept, Brussels, Belgium. ${ }^{14}$ University Respiratory Medicine Unit, Evgenidio Hospital, Athens, Greece.
\end{abstract}

Correspondence: Giovanni Battista Migliori, WHO Collaborating Centre for TB and Lung Diseases, Fondazione S. Maugeri IRCCS, Via Roncaccio 16, Tradate, Varese 21049, Italy. E-mail: giovannibattista.miglioriafsm.it

@ERSpublications

ERS and the European Region of The Union call for prioritisation of TB care, prevention and control among refugees http://ow.ly/YYCL8

Tuberculosis (TB) is a major cause of mortality from an infectious disease, globally affecting 9.6 million cases, with 1.5 million deaths in 2014 [1]. In 2014, there were 273381 TB cases reported in the World Health Organization (WHO) European region, and an estimated 33000 deaths [2]. Vulnerable populations (i.e. individuals affected by discrimination, hostility or economic adversity), which often include migrants and refugees, have an increased risk of suffering from TB disease [1, 3, 4]. If this is not efficiently addressed, the exposure of these groups to Mycobacterium tuberculosis strains may lead to a rise in the number of cases of disease and related deaths, as well as contributing to a further increase in drug-resistant TB cases.

Several factors have contributed to the increase of population mobility in the WHO European region [3]. This rise in the level of cross-border movement has increased the need for collaboration between national

Received: Feb 192016 | Accepted: Feb 242016 | First published online: March 242016

Christina Gratziou is the European Respiratory Society Advocacy Council Chair and Secretary for European Union Affairs 2015-2018

Conflict of interest: Brian Ward and Vitor Teixeira are employees of the European Respiratory Society. Further disclosures can be found alongside the online version of this article at erj.ersjournals.com

A press release for this article is available from erj.ersjournals.com/press

Copyright CERS 2016 
health systems. Sustainable and effective mechanisms are thus needed to coordinate interventions to ensure quality-based prevention, diagnosis and treatment for TB and latent TB infection (LTBI) $[5,6]$. These interventions represent both individual human rights (independent of legal or residential status of the subject) and public health pre-requisites to control and eliminate $\mathrm{TB}$, as well as to prevent further development of multidrug-resistant (MDR)-TB and extensively drug-resistant TB $[7,8]$.

For undocumented migrants, there is an urgent need for policies that will facilitate easy access to TB diagnosis and treatment, as well as stop deportation until the end of treatment. These interventions would be both in the interest of the individual and of the community in terms of TB control and elimination [9-13]. In 2015, more than one million migrants and refugees reached Europe by land and sea. In the whole of 2014, the figure was much lower $(219000)[4,14]$. In spite of the resolutions and statements recently released by WHO and the European Union [4, 15], little is known about the policies in force in the different countries in Europe to manage TB and LTBI among refugees [16, 17].

The following points should be noted. 1) The refugees' health is an integral part of the health of the wider community, as well as a human right $[3,9]$. 2) TB is neither highly virulent nor easily transmitted, and is treatable, and therefore efforts should be implemented to detect and treat it promptly. Provision of treatment is essential to break the transmission cycle. 3) Refugees who come from middle or high TB incidence countries, as well as those from low TB incidence countries who have travelled and lived in precarious conditions, have a higher risk of being infected and of developing TB than the population of the host country $[1,3,5,6] .4)$ The diagnosis of LTBI, TB and MDR-TB is not always easy to organise and perform in the centres hosting refugees upon arrival in Europe $[4,16,17]$ or as they travel through other countries. 5) Sub-optimal medical management of LTBI, TB and MDR-TB and/or inadequate follow-up of this mobile population could undermine TB prevention and control among refugees and the host society [3,9].

The European Respiratory Society and the European Region of the International Union Against TB and Lung Disease urge health authorities, national and international technical agencies and civil society organisations, as well as donor agencies, to prioritise TB care, prevention and control. They strongly recommend: 1) adapting and implementing the principles of the WHO End TB Strategy to ensure adequate prevention, diagnosis and treatment of TB (and of LTBI in the countries where these are offered) among refugees $[1,5]$; 2) providing quality surveillance, monitoring and evaluation, and operational research to enhance TB prevention, control and care among refugees; 3 ) ensuring timely screening for active TB among refugees coming from middle or high TB incidence countries; 4) avoiding stigmatisation and stereotypes of both TB-infected people and vulnerable groups; 5) promoting universal access to prevention, diagnosis and treatment services for LTBI (in the countries where these are offered) and TB, as well as to the necessary care of existing comorbidities [1,5]; and 6) ensuring quality infection control, including protective measures for staff, and providing HIV testing and counselling to detect HIV and TB/HIV co-infected individuals [18, 19].

\section{References}

1 World Health Organization. Global Tuberculosis Report 2015. WHO/HTM/TB/2015.22. Geneva, World Health Organization, 2015. Available from: www.who.int/tb/publications/global_report/en/

2 European Centre for Disease Prevention and Control, World Health Organization Regional Office for Europe. Tuberculosis surveillance and monitoring in Europe 2015. Stockholm, European Centre for Disease Prevention and Control, 2015. Available from: http://ecdc.europa.eu/en/publications/Publications/tuberculosis-surveillancemonitoring-Europe-2015.pdf

3 Dara M, de Colombani P, Petrova-Benedict R, et al. Minimum package for cross-border TB control and care in the WHO European region: a Wolfheze consensus statement. Eur Respir J 2012; 40: 1081-1090.

4 Matteelli A, Lönnroth K, Mosca D, et al. Cameroon's multidrug-resistant tuberculosis treatment programme jeopardised by cross-border migration. Eur Respir J 2016; 47: 686-688.

5 Lönnroth K, Migliori GB, Abubakar I, et al. Towards tuberculosis elimination: an action framework for low-incidence countries. Eur Respir J 2015; 45: 928-952.

6 Getahun H, Matteelli A, Abubakar I, et al. Management of latent Mycobacterium tuberculosis infection: WHO guidelines for low tuberculosis burden countries. Eur Respir J 2015; 46: 1563-1576.

7 International Organization for Migration. International Migration Law No. 25: Glossary on Migration. 2nd Edn. Geneva, International Organization for Migration, 2011. Available from: www.corteidh.or.cr/sitios/Observaciones/ 11/Anexo5.pdf

8 Dara M, Kluge H. Roadmap to prevent and combat drug-resistant tuberculosis. Copenhagen, World Health Organization Regional Office for Europe, 2011. Available from: www.euro.who.int/_data/assets/pdf_file/0014/ 152015/e95786.pdf

9 International Union Against Tuberculosis and Lung Disease. Recommendations to ensure the diagnosis and treatment of tuberculosis in undocumented migrants. Paris, International Union Against Tuberculosis and Lung Disease, 2008. Available from: www.theunion.org/get-involved/join-the-union/body/RESS_Undocumented-migrantsStatement_2008.pdf

10 Migliori GB, Zellweger JP, Abubakar I, et al. European Union Standards for Tuberculosis Care. Eur Respir J 2012; 39: 807-819.

11 van der Werf MJ, Sandgren A, D'Ambrosio L, et al. The European Union standards for tuberculosis care: do they need an update? Eur Respir J 2014; 43: 933-942. 
12 Migliori GB, Sotgiu G, D'Ambrosio L, et al. TB and MDR/XDR-TB in European Union and European Economic Area countries: managed or mismanaged? Eur Respir J 2012; 39: 619-625.

13 Veen J, Migliori GB, Raviglione M, et al. Harmonisation of TB control in the WHO European region: the history of the Wolfheze Workshops. Eur Respir J 2011; 37: 950-959.

14 United Nations High Commissioner for Refugees, The UN Refugee Agency. Refugees/migrants emergency response - Mediterranean. Regional overview. http://data.unhcr.org/mediterranean/regional.php. Date last updated: February 9, 2016. Date last accessed: February 9, 2016.

15 World Health Organization Sixty-Seventh World Health Assembly. Draft gobal strategy and targets for tuberculosis prevention, care and control after 2015. A67/11. Geneva, World Health Organization, 2014. Available from: http://apps.who.int/gb/ebwha/pdf_files/WHA67/A67_11-en.pdf

16 Schneeberger Geisler S, Helbling P, Zellweger JP, et al. Screening for tuberculosis in asylum seekers: comparison of chest radiography with an interview-based system. Int J Tuberc Lung Dis 2010; 14: 1388-1394.

17 de Vries G, van Rest J, Meijer W, et al. Low yield of screening asylum seekers from countries with a tuberculosis incidence of <50 per 100000 population. Eur Respir J 2016 [in press; DOI: 10.1183/13993003.00099-2016].

18 World Health Organization. WHO policy on collaborative TB/HIV activities: guidelines for national programmes and other stakeholders. WHO/HTM/TB/2012.1, WHO/HIV/2012.1. Geneva, World Health Organization, 2012. Available from: http://apps.who.int/iris/bitstream/10665/44789/1/9789241503006_eng.pdf

19 World Health Organization. WHO policy on TB infection control in health-care facilities, congregate settings and households. WHO/HTM/TB/2009.419. Geneva, World Health Organization, 2009. Available from: http://apps. who.int/iris/bitstream/10665/44148/1/9789241598323_eng.pdf 